\title{
CHEMOSPHERE
}

\section{NOM characteristics and treatabilities of ozonation processes}

\author{
P.C. Chiang ${ }^{a, *}$, E.E. Chang ${ }^{b}$, C.H. Liang ${ }^{a}$ \\ ${ }^{a}$ Graduate Institute of Environmental Engineering, National Taiwan University, 71 Chou-Shan Road, Taipei, Taiwan, ROC \\ ${ }^{\mathrm{b}}$ Department of Biochemistry, Taipei Medical University, Taipei, Taiwan, ROC
}

Received 12 April 2000; received in revised form 10 July 2001; accepted 12 July 2001

\begin{abstract}
The objectives of this study were intended to evaluate the effects of the characteristics of natural organic matter on the treatabilities of ozonation, coagulation, filtration, and granular activated carbon processes. The ultra-violet absorbance $\left(\mathrm{UV}_{254}\right)$ was used as a surrogate parameter to assess each process in reducing the disinfection by-product formation potential (DBPFP). The results indicate that the DBPFP varies with the sources of water samples and treatment processes, but is closely related to the measurement of $\mathrm{UV}_{254} / \mathrm{DOC}$. Coagulation/sedimentation can eliminate large molecular weight organic fractions. Both pre- and post-ozonation processes can reduce some of DBP precursors than the conventional treatment process, and are more reliable for reducing the overall DBPFP. () 2002 Elsevier Science Ltd. All rights reserved.
\end{abstract}

Keywords: Natural organic matter; Disinfection by-product; Molecular weight distribution; Disinfection by-product formation potential

\section{Introduction}

Natural organic matter (NOM) is a term used to describe the complex matrix of organic material present in natural waters; there exists a relationship between its characteristics and treatabilities (Owen et al., 1995). Molecular weight (MW) distribution of NOM is one of the important parameters in characterizing NOM (Amy et al., 1992; Newcombe et al., 1997). Another representative parameter is the chemical fractionation of NOM, which can influence the complexation of aluminum or iron (hydr)oxide (Tadanier et al., 1999), and the formation of disinfection by-product, DBP (Galapate et al., 2001). In water treatment processes, each unit process may exhibit different removal efficiencies for a specific MW fraction of NOM (Jacangelo et al., 1995). For example, some investigators have suggested that coagulation is suitable to treat a higher MW fraction of NOM.

\footnotetext{
${ }^{*}$ Corresponding author. Fax: +886-2-23661642.

E-mail address: d6541002@ms.cc.ntu.edu.tw (P.C. Chiang).
}

Unfortunately, the anticipated maximum contaminant levels for haloacetic acids (HAA) and trihalomethanes (THM) of certain source water may not be met by using enhanced coagulation (Crozes et al., 1995). Thus, the conventional water treatment process with coagulation/ sedimentation and filtration is unable to remove a significant amount of the NOM.

Because of the formation of DBP, more advanced technologies including oxidation, adsorption, membrane filtration were introduced to remove NOM prior to disinfection process. Ozone has been used as a strong oxidant for years, and several researchers (Jacangelo et al., 1989; Amy et al., 1991) have shown that ozonation prior to chlorination can lower the formation potential of THM and HAA. It has been reported that ozonation could convert NOM from humic substances to non-humic fractions and from higher- to lower-MW fractions (Amy et al., 1992; Owen et al., 1995). In the pre-ozonation process, ozone is added to the source water prior to coagulation. The role of ozone acts as an oxidant and sometimes as a coagulant-aid. The dosage of pre-ozonation to achieve the best coagulation ranges 
from 0.4 to $0.8 \mathrm{mg} \mathrm{O}_{3} / \mathrm{mg}$ carbon (Singer, 1990). During pre-ozonation, organics in terms of $\mathrm{UV}_{254}$ (ultraviolet absorbance) and, to a lesser extent, total organic halogen (TOX) and total organic carbon (TOC) are significantly reduced (Reckhow and Singer, 1984). In the post-ozonation process, ozone is added after the filtration process and prior to the activated carbon process. This could result in converting compounds to enhance the adsorption capacity of the granular activated carbon, GAC (Amy et al., 1991). Conversely, the end products of post-ozonation with higher polarity and solubility might reduce the adsorption efficiency of the GAC (Glaze and Wallace, 1984; Chang et al., 1995).

Many researchers have developed empirical formulas for predicting the disinfection by-product formation potential (DBPFP) based on the parameters including the nature of NOM, chlorine dosage (or demand), UV absorbency, TOC, contact time, $\mathrm{pH}$, and temperature (Edzwald et al., 1985; Urano and Takemasa, 1986; Amy et al., 1987; Korshin et al., 1997). However, the utilization of these correlation models is still limited since they are site-specific (Garcia-Villanova et al., 1997). Actual monitoring DBPFP of each process, particularly with respect to the effect of pre- or post-ozonation, is essential for the process evaluation.

The objectives of this research work are intended to: (1) investigate the NOM composition, i.e., MW and hydrophilic/hydrophobic distributions, of some source waters, (2) evaluate the effects of MW distribution on the treatabilities of ozonation, coagulation, filtration, and GAC processes, and then (3) compare the efficiency of each unit for controlling the formation of DBP and assess the feasibility of using $\mathrm{UV}_{254}$ as a surrogate parameter for determining the DBPFP.

\section{Materials and methods}

\subsection{Water samples}

The characteristics of NOMs were analyzed from the samples collected from the source water at major water treatment plants in Taiwan, i.e., groundwater (plants A, B), reservoir (plants C, D) and surface water (plants E, F), according to our previous work (Chang et al., 1997). The water treatment plants $\mathrm{C}$ and $\mathrm{E}$ are conventional plants with coagulation/sedimentation and sand filtration processes, located in Taipei City and Taipei County, respectively.

To evaluate the effect of ozonation, a lab-scale advanced treatment process was constructed on the site of Water Treatment Plant $\mathrm{C}$, including pre- and post-ozonation, coagulation/sedimentation, sand filtration and GAC adsorption. The flow diagrams of the conventional, pre-ozonation, and post-ozonation process are illustrated in Fig. 1(a)-(c), respectively. The ozone contactor glass column $(2.25 \mathrm{~m}$ height and $12.5 \mathrm{~cm}$ diameter) was operated in a counter-current mode, i.e., water flowing downward and gas through a ceramic diffuser flowing upward. Ozone gas and water were both added continuously into the contactor. The applied ozone dosage was about $1.2 \mathrm{mg} \mathrm{O}_{3} / \mathrm{mg}$ DOC (dissolved organic carbon) by changing gaseous ozone concentration. Because of low DOC content, the raw water of the Plant $\mathrm{C}$ was supplemented by adding commercial humic acid (Aldrich). The Aldrich humic acid has also been introduced as a larger MW organic component for ozonation test by Geol et al. (1995). It is noted that commercial humic substances have been found to be significantly different from the natural aquatic NOM, even the elemental contents are similar (Malcolm and MacCarthy, 1986).

The ozone dosage, initial DOC concentrations, and other operating conditions are shown in Table 1. Additionally, water samples were collected from each process effluent of the water treatment plant $\mathrm{E}$ to evaluate the performance of the individual unit operation.

\subsection{NOMs characteristics}

The ultra-filtration (UF) membranes (A/G Technology), hollow-fiber modules with nominal molecular weight cut-off of $1,5,10$ and $30 \mathrm{kDa}$, were used to fractionate NOM. Each membrane was composed of cellulose derivative with a total surface area of $24 \mathrm{~cm}^{2}$. The applied pressure through the membranes ranged from 270 to $350 \mathrm{kPa}$, and the filtrate was concentrated by a rotary vacuum evaporator. The concentrated filtrate was diluted with deionized water (Milli-Q) and then analyzed for DOC and DBPFP. As suggested by Amy et al. (1990), the UF fraction technique does not provide discrete MW fractions but instead generates a series of cumulative ones. In this research, the amount of DOM associated with each cumulative fraction was determined by measurement of the respective permeates (Newcombe et al., 1997).

The DAX-8 resin (SULPECO) was used to fractionate NOM following the procedure of Thurman and Malcolm (1981). Water samples were pre-filtered (Whatman GF/C) to remove particles and filtrated to a DAX-8 packed column I; the hydrophobic base group would be absorbed by the resin. Column I effluent $\mathrm{pH}$ was adjusted to 2 using $\mathrm{HCl}$ before introducing into Column II; the Column II effluent contained hydrophilic groups. Use $0.1 \mathrm{~N} \mathrm{HCl}$ to elute the resin of Column I to acquire the hydrophobic base group; and use $0.1 \mathrm{~N}$ $\mathrm{NaOH}$ to backwash the resin of Column II to acquire the hydrophobic acid group. Finally, dry the resin of column II at $60{ }^{\circ} \mathrm{C}$ for $72 \mathrm{~h}$ and then extract with dehydrated methanol; the extraction was classified as the hydrophobic neutral. 


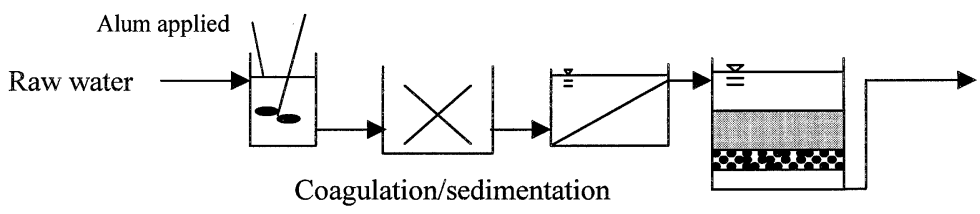

(a) Sand filtration

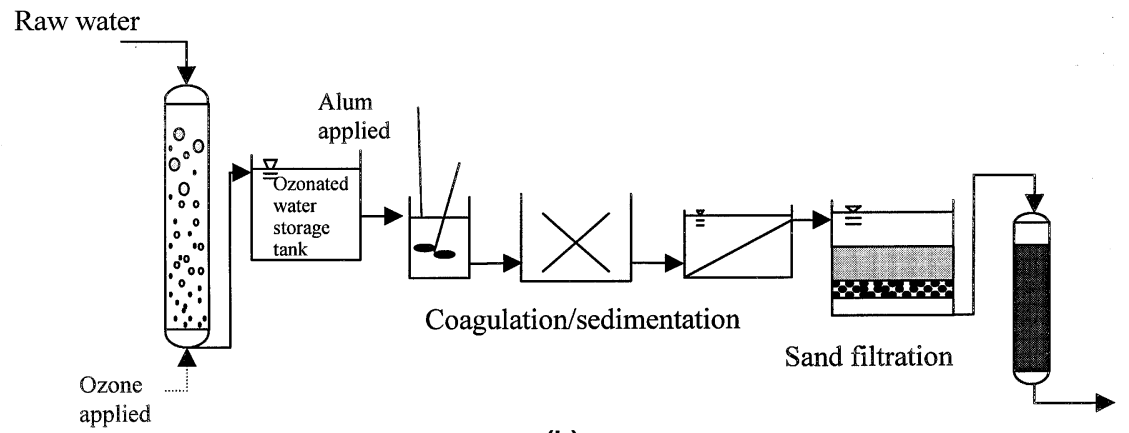

(b)

GAC

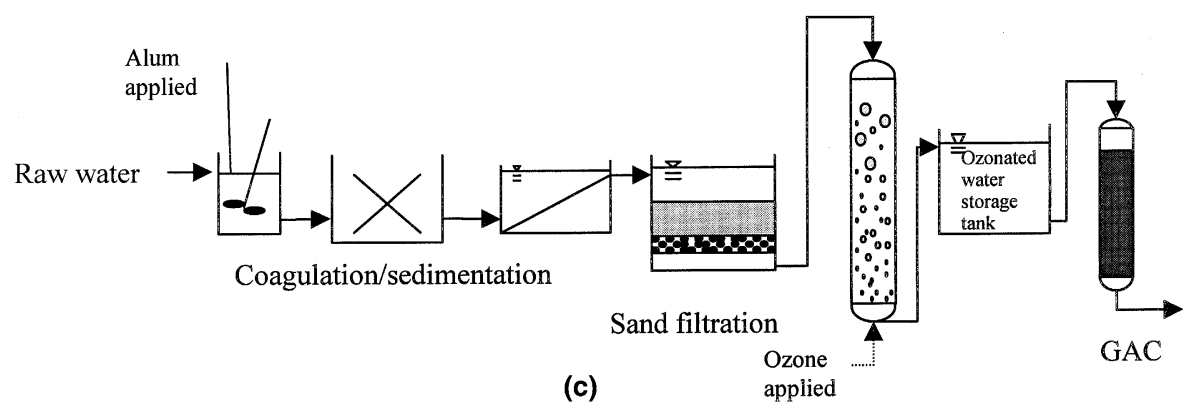

Fig. 1. Unit process diagrams of the treatment process: (a) conventional, (b) pre-ozonation, (c) post-ozonation.

Table 1

Operating conditions and sampling locations of the lab-scale ozonation processes

\begin{tabular}{llllll}
\hline Raw water & DOC $_{0}(\mathrm{mg} / \mathrm{l})$ & Process & $Q_{1}(1 / \mathrm{min})$ & $\begin{array}{l}\text { Ozone dosage } \\
\left(\mathrm{mg} \mathrm{O}_{3} / \mathrm{mg} \text { DOC }\right)\end{array}$ & $\begin{array}{l}\text { Sampling } \\
\text { locations }\end{array}$ \\
\hline Plant C source & 7.0 & Conventional & 2 & - & $\mathrm{R}, \mathrm{C}, \mathrm{F}, \mathrm{G}$ \\
Water + & 6.9 & Pre-ozonation & 2 & 1.1 & $\mathrm{R}, \mathrm{O}, \mathrm{C}, \mathrm{F}, \mathrm{G}$ \\
Aldrich HA & 7.0 & Post-ozonation & 2 & 1.2 & $\mathrm{R}, \mathrm{C}, \mathrm{F}, \mathrm{O}, \mathrm{G}$ \\
\hline
\end{tabular}

$\mathrm{R}$ : raw water, $\mathrm{C}$ : coagulation (alum dose $=1.2 \mathrm{mg} / \mathrm{l}$ as $\mathrm{Al}^{3+}$ ), $\mathrm{F}$ : sand filtration (filtration rate $=120 \mathrm{~m} / \mathrm{day}$ ), G: GAC (empty bed contact time $=2 \mathrm{~min}$, hydraulic loading rate $=8 \mathrm{~m} / \mathrm{h}$ ), O: pre-ozonation or post-ozonation.

The columns were 3 -cm-diameter and $50-\mathrm{cm}$-height glass chromatographic columns with PTFE caps. Water samples were pumped by peristaltic pumps and controlled at $100 \mathrm{ml} / \mathrm{min}$ flow rate. The eluates were concentrated by a rotary vacuum evaporator. The concentrated eluates were diluted with deionized water and then chlorinated with $\mathrm{NaOCl}$ for the DBPFP test. As a result, THM and HAA formation potentials of each of four NOM fractionations, i.e., hydrophilic, hydrophobic basic, hydrophobic neutral and hydrophobic acidic groups, for the source water of the Plant $\mathrm{C}$ were determined.

\subsection{Analytical methods}

DBPFP including THM and HAA formation potential was measured after a 7-day incubation period with sodium hyperchlorite (Merck) solution according to Standard Methods (APHA, 1992). THM samples were extracted with $n$-pentane, and the extract was then 
analyzed by gas chromatograph (HP 5180-II) with a fused silica capillary column (Restek Mtx-5, $30 \mathrm{~m} \times 0.28$ $\mathrm{mm}$ ID, and $1.0 \mu \mathrm{m}$ film thickness) and an electronic capture detector. A microextraction procedure (extracting with methyl-tert-butyl ether and esterfied with diazomethane) was used to analyze HAA. Samples were filtrated through $0.45 \mu \mathrm{m}$ membrane and filtrate was then analyzed by a wet-oxidation method (O.I.C. Model 700) for DOC. The QA/QC programs set forth in Standard Methods including detection limits, internal standard, surrogate standard and preservative agents for DBPs were followed.

\section{Results and discussions}

\subsection{Effects of molecular weight on DBPFP reduction}

The MW distributions of NOMs are presented in Fig. 2(a). It is obvious that compounds present in surface water (plants E and F) consist of smaller molecules $(<1 \mathrm{kDa})$ and larger ones $(>30 \mathrm{kDa})$. Previous studies (Amy et al., 1990, 1991) also reported that low MW fraction was predominant for surface water samples. On the other hand, MW distributions of two reservoir water samples (plants C and D) were relatively even, but samples from groundwater (plants $\mathrm{A}$ and $\mathrm{B}$ ) containing lower molecular weights less than $1 \mathrm{kDa}$ has the highest concentration level of DOC. These results are quite
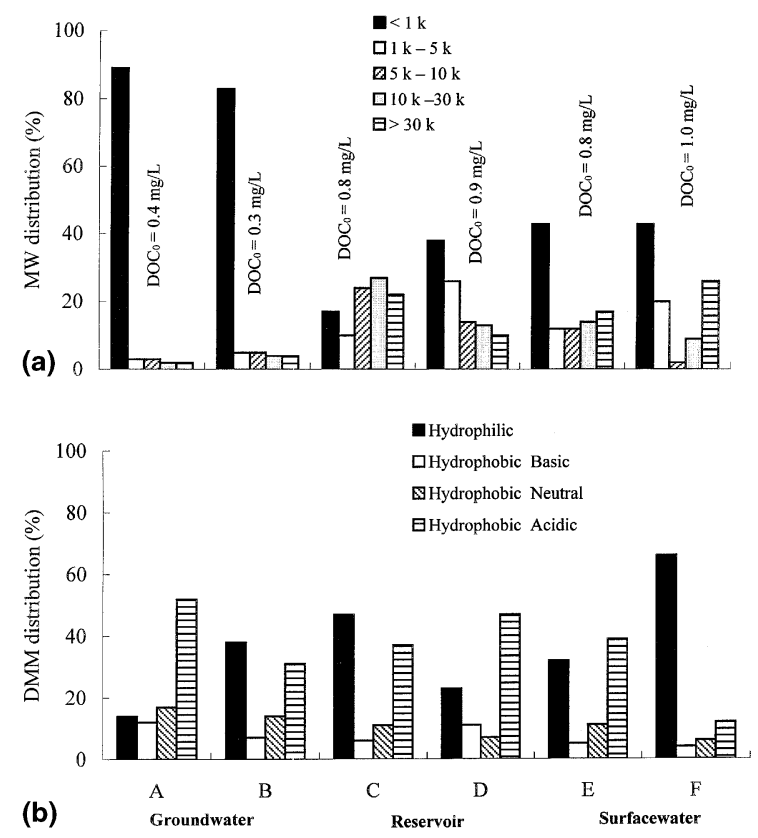

Fig. 2. NOMs characteristics for source water at different water treatment plants: (a) molecular weight distribution, (b) dissolved material matrix. different from other studies (Amy et al., 1992; Newcombe et al., 1997), which suggest that the MW characteristics are site specific. The MW fraction affecting the performance of different treatment processes is discussed later.

Tadanier et al. (1999) analyzed the source water from Drummond Lake and Chickahominy River (Virginia), and reported that the hydrophobic acid dissolved material matrix (DMM) fraction dominated the dissolved organic matter (DOM) distributions, followed by the hydrophilic neutral fraction. The remaining DMM fractions contributed $<10 \%$ of the DOM. In Taiwan, Huang and Yeh (1997) reported that hydrophobic organics from Feng-San Stream yielded higher halogenated organics formation potential because of its higher aromatic content, phenolic acidity, and ultraviolet adsorbance. In this research, the hydrophobic groups fractionated by DAX-8 resins are more commonly observed than the hydrophilic group except for the Plant F (Fig. 2(b)). Furthermore, it is evident that the acidic fraction of the hydrophobic group is dominant.

The average and standard deviation (error bar) of DBPFPs per unit DOC of each hydrophilic-hydrophobic fraction of Plant $\mathrm{C}$ source water are shown in Fig. 3, which implies that most of THM precursors are concentrated in the hydrophobic acid group $(194 \mu \mathrm{g} / \mathrm{mg})$, and least of them is in the hydrophilic fractionation (39 $\mu \mathrm{g} / \mathrm{mg})$. Similar observation is also noted for HAAFP. Thus, removal of the hydrophobic acid fraction in
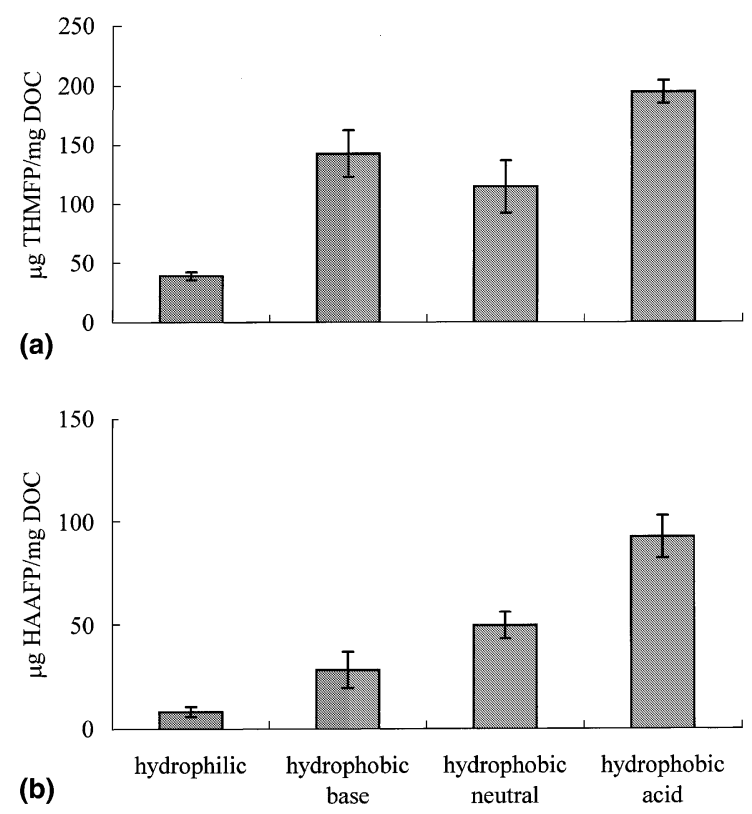

Fig. 3. The occurrence of: (a) THMFP, (b) HAAFP at unit concentration of DOC and NOM fractionation (plant $\mathrm{C}$ source water). 
Table 2

Fractions of DOC and DBPFP containing in various types of water samples with different molecular weight distribution

\begin{tabular}{|c|c|c|c|}
\hline \multirow{2}{*}{$\begin{array}{l}\text { Organic } \\
\text { parameter }\end{array}$} & \multirow{2}{*}{$\begin{array}{l}\text { MW } \\
(\mathrm{kDa})\end{array}$} & \multicolumn{2}{|c|}{ Constituent distribution percentage $(\%)$} \\
\hline & & $\begin{array}{l}\text { Plant C + Aldrich HA } \\
\left(\mathrm{DOC}_{0}=6.9 \mathrm{mg} / \mathrm{l}\right)\end{array}$ & $\begin{array}{l}\text { Plant E }\left(\mathrm{DOC}_{0}\right. \\
=0.8 \mathrm{mg} / \mathrm{l})\end{array}$ \\
\hline \multirow[t]{5}{*}{ DOC } & $<1$ & 20 & 43 \\
\hline & $1-5$ & 5 & 12 \\
\hline & $5-10$ & 7 & 14 \\
\hline & $10-30$ & 20 & 14 \\
\hline & $>30$ & 46 & 17 \\
\hline \multirow[t]{5}{*}{ TCMFP } & $<1$ & 17 & 62 \\
\hline & $1-5$ & 2 & 16 \\
\hline & $5-10$ & 6 & 8 \\
\hline & $10-30$ & 21 & 6 \\
\hline & $>30$ & 53 & 8 \\
\hline \multirow[t]{5}{*}{ DCAAFP } & $<1$ & 21 & 65 \\
\hline & $1-5$ & 2 & 7 \\
\hline & $5-10$ & 8 & 13 \\
\hline & $10-30$ & 29 & 8 \\
\hline & $>30$ & 39 & 7 \\
\hline \multirow[t]{5}{*}{ TCAAFP } & $<1$ & 10 & 60 \\
\hline & $1-5$ & 2 & 11 \\
\hline & 5-10 & 5 & 8 \\
\hline & $10-30$ & 30 & 13 \\
\hline & $>30$ & 51 & 8 \\
\hline
\end{tabular}

different water treatment processes is the key to reduce the level of DBPs in the treated water.

The percentages of DBPFP at various MW ranges of organic matter of the Plant E source water and humic acid-supplemented Plant $\mathrm{C}$ source water are shown in Table 2. It is clear that commercial humic substances (Aldrich) contain higher concentrations of DOC in the MW fraction $>30 \mathrm{kDa}(46 \%)$. Accordingly, the distribution ratios of tricholomethane formation potential (TCMFP), trichloroacetic acid formation potential (TCAAFP) and dichloroacetic acid formation potential (DCAAFP) are $53 \%, 51 \%$ and $39 \%$, respectively. On the contrary, the DBP precursor distributions of the Plant E source water constitute most of low MW organics $(46 \%<1 \mathrm{kDa})$. The total DBPFP (TCMFP, DCAAFP and TCAAFP) in the MW fraction $<1 \mathrm{kDa}$ is about $63 \%$.

\subsection{Effect of unit process on reductions of DOC and $D B P F P$}

Fig. 4(a) shows the changes of DOC concentration of the corresponding MW constituent after the pre-ozonation process. The pre-ozonation process effectively reduces large MW organics $(>10 \mathrm{kDa})$ and converts them to smaller ones, resulting in increases in the MW
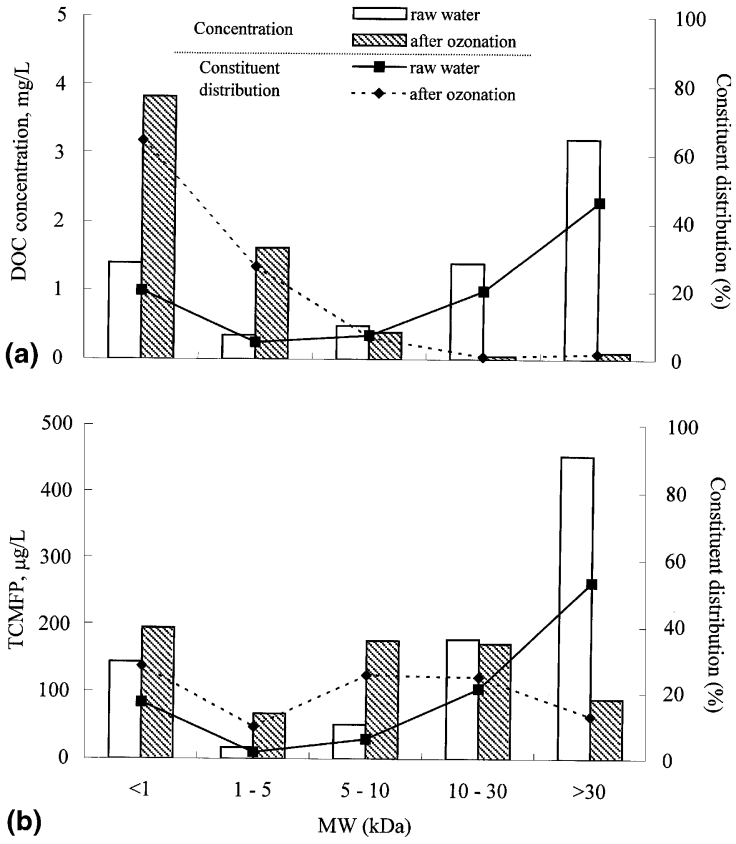

Fig. 4. The concentration and constituent distribution of raw water (plant $\mathrm{C}+$ Aldrich-HA, $\mathrm{DOC}_{0}=6.9 \mathrm{mg} / \mathrm{l}$ ) and after preozonation treatment in the pilot plant. (a) DOC, (b) TCMFP.

fraction $<5 \mathrm{kDa}$. As a result, the DOC concentration of the MW fraction <1 kDa increases from 1.4 to $3.8 \mathrm{mg} / \mathrm{l}$, or from $24 \%$ to $63 \%$. Analogous to the DOC, the TCMFP of the MW fractions $>30 \mathrm{kDa}$ is effectively reduced by pre-ozonation (the reduction efficiency is about $80 \%$ ) and those of MW fractions $<10 \mathrm{kDa}$ increase after ozonation (Fig. 4(b)). Overall, the results indicate that pre-ozonation is able to reduce DOC from 6.9 to $6.0 \mathrm{mg} / \mathrm{l}$ and TCMFP from 847 to $704 \mu \mathrm{g} / \mathrm{l}$.

Water samples from coagulation and filtration units at a full-scale conventional plant (plant E) were collected to evaluate the DOC reduction capability of these processes. The DOC distributions with respect to each MW fraction and its corresponding reduction efficiency are shown in Fig. 5(a). The coagulation is able to remove large MW fractions ( $>30 \mathrm{kDa})$ with about $59 \%$ DOC reduction, as compared to $7 \%$ elimination for the $\mathrm{MW}$ fraction $<1 \mathrm{kDa}$. As would be expected, the performance of DOC reduction in the filtration process is insignificant and not affected by the MW distribution of the NOM. Thus, the conventional process has poor capability to eliminate small MW organics, which will be present in the finished water. In the coagulation process, the reduction efficiencies of TCMFP for MW fractions $>30 \mathrm{kDa}$ and $<1 \mathrm{kDa}$ are about $64 \%$ and $12 \%$, respectively (Fig. 5(b)).

Figs. 6(a) and (b) show the formation potential of TCM, DCAA and TCAA in the effluents of each process of the post- and pre-ozonation schemes. In the 

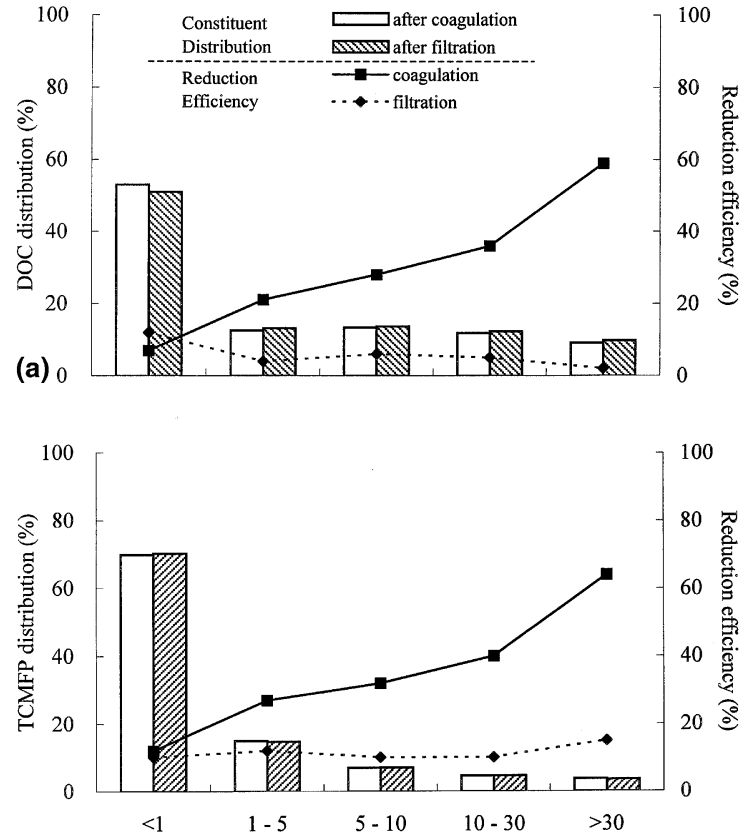

(b)

MW (kDa)

Fig. 5. The concentration distribution and reduction efficiencies in a full-scale conventional process (plant $\mathrm{E}, \mathrm{DOC}_{0}=0.8$ $\mathrm{mg} / \mathrm{l}$ ). (a) DOC, (b) TCMFP.

post-ozonation process (Fig. 6(a)), the trend of formation potential of different compounds (TCM, DCAA, and TCAA) is consistent with the variation of $\mathrm{UV}_{254}$ except for DCAAFP. Similar observations were also noted in the pre-ozonation process (Fig. 6(b)).

The reduction efficiencies of THMFP and HAAFP in the pre- and post-ozonation processes are assessed by the reduction ratios of $\mathrm{UV}_{254}$ and DOC. The correlations are:

\section{(Removal efficiency of THMFP)}

$$
\begin{aligned}
= & 0.04 \times(\text { Removal efficiency of } \mathrm{DOC})^{0.43}+0.58 \\
& \times\left(\text { Removal efficiency of } \mathrm{UV}_{254}\right)^{0.94} ; \\
& R^{2}=0.902,
\end{aligned}
$$

(Removal efficiency of HAAFP)

$$
\begin{aligned}
= & 0.05 \times(\text { Removal efficiency of DOC })^{0.25}+0.49 \\
& \times\left(\text { Removal efficiency of } \mathrm{UV}_{254}\right)^{1.00} ; \\
& R^{2}=0.881 .
\end{aligned}
$$

The results demonstrate that there is good correlation among the removal efficiencies of THMFP (or HAAFP), DOC and $\mathrm{UV}_{254}$ parameters; the last two parameters provide easy measurement and serve as an operational guideline to the operator for controlling DBP formation in water treatment plants.

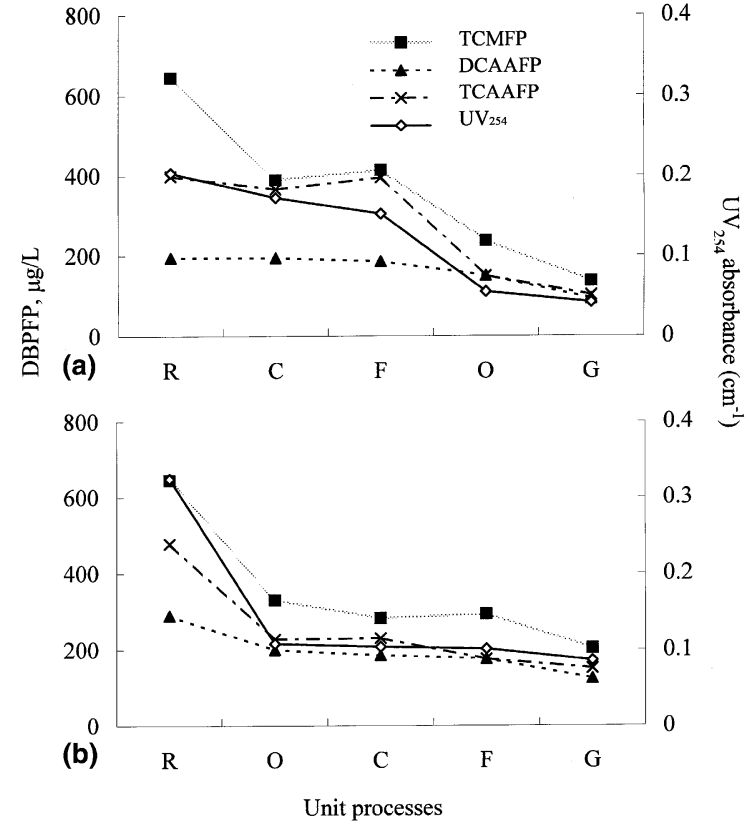

Fig. 6. The changes of DBPFP and $\mathrm{UV}_{254}$ absorbance in the effluents of each treatment unit. (a) post-ozonation (plant $\mathrm{C}+$ Aldrich-HA, $\mathrm{DOC}_{0}=7.0 \mathrm{mg} / \mathrm{l}$ ), (b) pre-ozonation processes (plant $\mathrm{C}+$ Aldrich-HA, $\mathrm{DOC}_{0}=6.9 \mathrm{mg} / \mathrm{l}$ ) R: raw water, C: coagulation, F: sand filtration, O: post-ozonation, G: GAC.

It is also evident from Fig. 6 that the effective process to reduce HAAFP is the ozonation or GAC. For example, pre-ozonation provides additional reduction effect in further reducing DCAAFP and TCAAFP; thus the entire performance is better than that of the conventional process for controlling HAAFP. In short, both pre- and post-ozonation processes can be successfully employed in reducing THMFP with respect to DCAAFP and TCAAFP.

The reduction efficiency of DBPFP at each unit process was evaluated by $\mathrm{UV}_{254}$ per unit DOC. The results indicate that there is a significant decrease of $\mathrm{UV}_{254} / \mathrm{DOC}\left(0.053-0.015 \mathrm{~cm}^{-1} / \mathrm{mg}\right)$ after the pre-ozonation process (Table 3). There is no reduction of $\mathrm{UV}_{254} / \mathrm{DOC}$ in the coagulation, filtration and GAC for the pre-ozonation processes. The $\mathrm{UV}_{254} / \mathrm{DOC}$ ratio is also reduced by the post-ozonation process $(0.041$ to $0.024 \mathrm{~cm}^{-1} / \mathrm{mg}$ ). This evidence suggests that both preand post-ozonation can effectively lower the $\mathrm{UV}_{254} /$ DOC values, thus reducing the DBPFP through converting DBP precursors to non-precursors. It is noted that GAC also reduces $\mathrm{UV}_{254} / \mathrm{DOC}$ in the post-ozonation system, apparently due to the ozone role in modifying compound absorbability.

The total reduction efficiencies of THMFP, DCAAFP, and TCAAFP at different treatment processes are shown in Fig. 7. It is obvious that both pre- and post- 
Table 3

Values of $\mathrm{UV}_{254} / \mathrm{DOC}\left(\mathrm{cm}^{-1} / \mathrm{mg}\right)$ in different effluents of each unit process

\begin{tabular}{llllllll}
\hline Processes & $\begin{array}{l}\mathrm{DOC}_{0} \\
(\mathrm{mg} / \mathrm{l})\end{array}$ & $\mathrm{UV}_{254} / \mathrm{DOC}$ & & & & \\
\cline { 3 - 8 } & & Raw water & Pre-ozonation & Coagulation & Sand filtration & Post-ozonation & GAC \\
\hline Pre-ozonation & 6.9 & 0.053 & 0.014 & 0.014 & 0.014 & - & 0.015 \\
Conventional & 7.0 & 0.052 & - & 0.043 & 0.041 & - & 0.026 \\
Post-ozonation & 7.0 & 0.052 & - & 0.043 & 0.041 & 0.024 & 0.012 \\
\hline
\end{tabular}

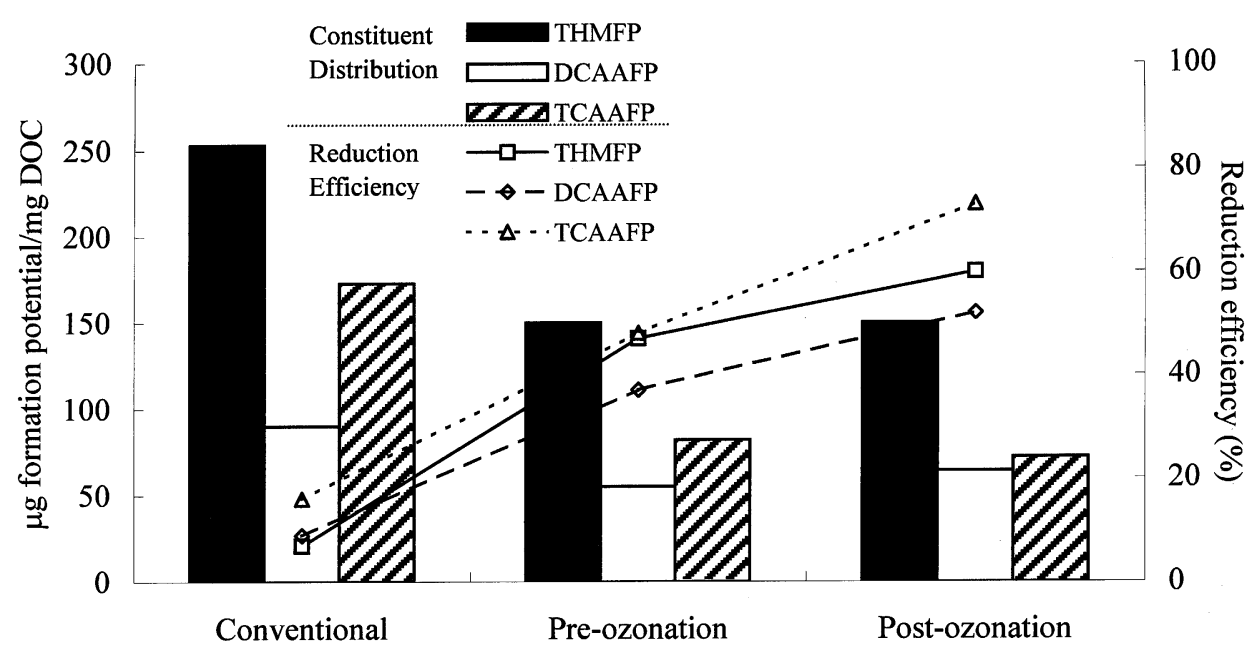

Fig. 7. The concentrations of DBPFP per unit weight DOC in the finished water by the three treatment processes (plant $\mathrm{C}+\mathrm{Aldrich}-$ HA).

ozonation processes are more effective in removing organic precursors than the conventional treatment process. This is due to the oxidation of organics, as well as enhancement of the GAC adsorption performance after ozonation. It is also evident that the concentration of DBPFP per unit weight of DOC in the finished water of the conventional process is the highest. In summary, the advanced treatment processes used in the present study are reliable alternatives in reducing the DBPFP.

\section{Conclusions}

Groundwater containing lower MW distributions less than $1 \mathrm{kDa}$ has the highest concentration level of DOC. On the other hand, MWs of reservoir water are evenly distributed, while samples from surface water have more smaller molecules $(<1 \mathrm{kDa})$ and larger ones $(>30 \mathrm{kDa})$. The DMM characteristics of source water indicate that the hydrophobic groups are more commonly observed than the hydrophilic group except for Plant F. The THM and HAA formation potentials of Plant C source water imply that most of THM precursors are concentrated in the hydrophobic acid group, and least of them in the hydrophilic fraction. The coagulation processes can provide efficient reduction of DOC and DBPFP only for large MW organics; moreover, ozonation can convert large MW compounds to small ones.

Although the characteristics of the DBPFP vary with the source of water samples, they are closely related to the measurement of $\mathrm{UV}_{254}$. Therefore, $\mathrm{UV}_{254} / \mathrm{DOC}$ can be used to evaluate the effectiveness of water purification processes in removing DBPFP. For advanced processes, both pre- and post-ozonation can effectively reduce DBP precursors.

\section{References}

Amy, G.L., Chadik, P.A., Chowdhury, Z.K., 1987. Developing models for predicting trihalomethane formation potential and kinetics. J. Am. Water Works Assoc. 79 (7), 89-97.

Amy, G.L., Thompson, J.M., Tan, L., Davis, M.K., Krasner, S.W., 1990. Evaluation of THM precursor contributions from agriculture drains. J. Am. Water Works Assoc. 82 (1), 57-64.

Amy, G.L., Tan, L., Davis, M.K., 1991. The effects of ozonation and activated carbon adsorption on trihalomethane speciation. Water Res. 25 (2), 191-202. 
Amy, G.L., Sierka, R.A., Bedessem, J., Price, D., Tan, L., 1992. Molecular size distributions of dissolved organic matter. J. Am. Water Works Assoc. 84 (6), 67-75.

APHA, 1995. Standard Method for the Examination of Water and Wastewater, 19th ed. American Public Health Association, Washington, DC.

Chang, E.E., Tiao, H.H., Ko, Y.W., Chiang, P.C., 1995. Effects of preozonation on activated carbon and adsorption of organic precursors. Water Supply 13 (3/4), 177-182.

Chang, E.E., Chiang, P.C., Liang, C.H., 1997. The occurrence of disinfection by-products in Taiwan drinking water. Toxicol. Environ. Chem. 67 (3), 333-349.

Crozes, G., White, P., Marshall, M., 1995. Enhanced coagulation: its effect on NOM removal and chemical costs. J. Am. Water Works Assoc. 87 (1), 78-89.

Edzwald, J.K., Beker, W.C., Wattier, L., 1985. Surrogate parameters for monitoring organic matter and THM precursor. J. Am. Water Works Assoc. 77 (4), 122-131.

Galapate, R.P., Baes, A.U., Okada, M., 2001. Transformation of dissolved organic matter during ozonation: effects on trihalomethane formation potential. Water Res. 35 (9), 2201-2206.

Garcia-Villanova, R.J., Gacia, C., Gomes, J.A., Gacia, M.P., Ardanuy, R., 1997. Formation, evolution and modeling of trihalomethanes in the drink water of a town: I. At the municipal treatment utilities. Water Res. 31 (6), 1299-1308.

Geol, S., Hozalski, R.M., Bouwer, E.J., 1995. Biodegradation of NOM: effect of NOM source and ozone dose. J. Am. Water Works Assoc. 87 (1), 90-105.

Glaze, W.H., Wallace, J.L., 1984. Control of trihalomethane precursors in drinking water: granular activated carbon with and without preozonation. J. Am. Water Works Assoc. 76 (2), 68-75.

Huang, W.J., Yeh, H.H., 1997. The effect of organic characteristics and bromide on disinfection by-products forma- tion by chlorination. J. Environ. Sci. Health A 32 (8), 23112336.

Jacangelo, J.G., Patania, N.L., Reagau, K.M., Aieta, E.M., Krasner, S.W., McGuire, M.J., 1989. Ozonation: assessing its role in the formation and control of disinfection byproducts. J. Am. Water Works Assoc. 81 (8), 74-84.

Jacangelo, J.G., DeMarco, J., Owen, D.M., Randtke, S.J., 1995. Selected processes for removing NOM: an overview. J. Am. Water Works Assoc. 87 (1), 64-77.

Korshin, G.V., Li, C.W., Benjamin, M.M., 1997. The decrease of UV absorbance as an indicator of TOX formation. Water Res. 31 (4), 946-949.

Malcolm, R.L., MacCarthy, P., 1986. Limitations in the use of commercial humic acids in water and soil research. Environ. Sci. Technol. 20 (9), 904-911.

Newcombe, G., Drikas, M., Assemi, A., Beckett, R., 1997. Influence of characterized natural organic material on activated carbon adsorption: I. characterization of concentrated reservoir water. Water Res. 31 (5), 965-972.

Owen, D.M., Amy, G.L., Chowdhury, Z.K., Paode, R., McCoy, G., Viscosil, K., 1995. NOM characterization and treatability. J. Am. Water Works Assoc. 87 (1), 46-63.

Reckhow, D.A., Singer, P.C., 1984. The removal of organic halide precursors by preozonation and alum coagulation. $\mathbf{J}$. Am. Water Works Assoc. 76 (4), 151-157.

Singer, P.C., 1990. Assessing ozonation research needs in water treatment. J. Am. Water Works Assoc. 82 (10), 78-88.

Tadanier, C.J., Berry, D.F., Knocke, W.R., 1999. Dissolved component recovery following resin exchange based DOM fractionation. J. Environ. Eng. 125 (10), 933-943.

Thurman, E.M., Malcolm, R.L., 1981. Preparative isolation of humic substances. Environ. Sci. Technol. 15 (5), 463-466.

Urano, K., Takemasa, T., 1986. Formation equation of halogenated organic compounds when water is chlorinated. Water Res. 20 (12), 1555-1560. 